\title{
Uninsured Patient Opinions about a Reduced-Fee Retainer Program at Academic Health Center Clinics
}

\author{
John W. Saultz, MD, John Heineman, BA, Rachel Seltzer, MA, Arwen Bunce, MA, \\ LeNeva Spires, BA, and Jennifer DeVoe, MD, DPhil
}

Background: Access Assured, an experimental program to deliver primary care to uninsured patients using a monthly retainer payment system, has been shown to provide a financially viable method of delivering primary care services to people without health insurance. This qualitative study was designed to assess patient attitudes and concerns about this program and to identify ways to improve it.

Methods: We conducted telephone interviews with 40 purposefully selected Access Assured members between May and June of 2009. This population was stratified to include a sample of 20 patients from those who had elected to renew enrollment in the program after their first 6-month enrollment period. The other 20 patients were selected from those enrollees who had not re-enrolled in the program after this initial period. The semistructured interviews were based on an original list of 19 standardized questions, which were asked of each participant. All interviews were audio taped. The interview tapes were transcribed verbatim and content analysis was conducted using immersion-crystallization methods.

Results: Content analysis identified 9 themes related to patient attitudes and concerns about this program. (1) Patients could not understand why they needed to remain enrolled if they were bealthy. (2) Patients had variable levels of personal agency or responsibility for their own care. (3) Patients reported they had no choice and needed to enroll in the program to have access to care. (4) Patients liked that the program allowed them to choose their provider and see that provider with continuity from visit to visit. (5) Patients felt they were respected and treated the same as other patients. (6) Patients expressed appreciation for the program. (7) Patients had a range of comments about the quality of care and service they received. (8) Patients reported confusion about the rules of the program and often did not understand its terms and benefits. (9) Patients were under personal and family economic stress. Twenty of the subjects in our study had re-enrolled in Access Assured and 11 of the 20 patients who had not re-enrolled expressed an intention to do so.

Conclusions: Our study population expressed gratitude and other positive opinions about the retainerbased program for uninsured patients in 2 academic family medicine clinics. Conversely, some were concerned about the perceived lack of choice related to enrollment. Significant gaps in patient understanding about the program were identified. Based on these results, we have made improvements to the program and plan to continue to offer this care model to uninsured patients in our practices. ( $\mathrm{J}$ Am Board Fam Med 2011;24:304-312.)

Keywords: Primary Health Care, Retainer Practice, Uninsured

Millions of Americans currently lack health insurance, ${ }^{1}$ and many have had difficultly accessing pri-

This article was externally peer reviewed.

Submitted 29 September 2010; revised 7 February 2011; accepted 14 February 2011.

From the Department of Family Medicine, Oregon Health \& Science University, Portland.

Funding: The Research Program at Oregon Health \& Science University's Department of Family Medicine supported this study. Two authors (JH and $\mathrm{AB}$ ) were supported by the Oregon Clinical and Translational Research Institute, grant nos. TL1 RR024159 and UL1 RR024140, from the National mary care services. ${ }^{2}$ To address the barriers to primary care that often result from being unin-

Center for Research Resources, a component of the National Institutes of Health (NIH) and NIH Roadmap for Medical Research. One author (JD) was supported partially by 1-K08HS16181 from the Agency for Healthcare Research and Quality. Conflict of interest: none declared.

Corresponding author: John W. Saultz, MD, Department of Family Medicine, Oregon Health \& Science University, 3181 SW Sam Jackson Park Rd, Mail Code: FM, Portland, OR 97239 (E-mail: saultz@ohsu.edu). 
sured, new programs have been created that allow uninsured patients to access care and "retain" physician services through the use of retainer payment systems. ${ }^{1,3-5}$ As health reform efforts to extend insurance coverage to more Americans gain momentum, the demand for more affordable types of insurance plans likely will continue.

The retainer model of practice started in private practice settings to expand access to a personal physician. $^{5-9}$ Often termed "concierge" or "boutique" practice, these programs usually involve monthly payments from the patient in exchange for access to a predefined basket of services. Such services might include expanded access to care after hours, E-mail and telephone advice from physicians, and home care options in addition to traditional office visits. Though the details and offerings of retainer practices vary, most are structured to allow patients to pay a fee, usually prepaid in 6- or 12-month increments, for expanded primary care services. ${ }^{5}$ Two recent articles have described the development of retainer practices in the setting of an academic health center. ${ }^{3,4}$

In February 2008, the Department of Family Medicine at Oregon Health \& Science University (OHSU) instituted a pilot retainer practice program, Access Assured, to improve access to primary care for patients without health insurance. ${ }^{3}$ Access Assured allows uninsured people to enroll as patients in one of 2 academic family medicine clinics for a fixed monthly fee. Once they are enrolled in the program, these patients are able to receive office-based primary care on a sliding fee scale, discounting their visit fees between $0 \%$ and $100 \%$, depending on their reported income. Access Assured enrollees are also able to receive telephone advice, prescription refills, and to contact providers using electronic communication without additional fees. In a previous article we reported the financial results after the first year of this program and described the demographic characteristics of those who enrolled. ${ }^{3}$

\section{Description of Access Assured}

Beginning on February 1, 2008, all uninsured patients requesting appointments in 2 family medicine clinics operated by the OHSU Department of Family Medicine were advised that appointments were only available if they were insured by a health plan that contracted with our practices or if they joined the Access Assured program. Joining Access Assured required each person to pay a fee of $\$ 25$ per month for a minimum of 6 months (\$150), and we provided a $\$ 25$ discount for those who chose to enroll for 12 months, thus enabling them to pay $\$ 275$ for a full year of membership. Patients who chose not to pay this fee were directed to safety net practices in the area, including a clinic staffed by faculty and resident physicians from our department. Access Assured members were then allowed to schedule as many office appointments as they wanted and to use our 24-hour telephone triage line, asynchronous secure E-mail access to their physicians, and our prescription refill system. The members were given a written description of the program and they were instructed that their membership fee did not cover any other services, such as fees associated with clinician visits, prescription drugs, specialist visits, or laboratory or radiograph charges. They were further instructed that their clinic visit fee would be determined by the OHSU charity policy, which features a sliding fee schedule based on income.

The policy requires financial needs assessments at the time of each visit for all patients without health insurance. Based on these assessments, visits are provided at a graduated discount rate, from a complete discount of $100 \%$ of all charges (all fees waived) for patients with incomes below $200 \%$ of the federal poverty level (FPL) $(\$ 44,100$ for a family of $4^{10}$ ) to a $10 \%$ discount for those between $385 \%$ and $400 \%$ of the FPL $(\$ 88,200$ for a family of 4) and no discount for all patients earning more than $400 \%$ of the FPL. Thus, full fees for office visits were charged for Access Assured members above $400 \%$ of the FPL and there were no visit charges for those below $200 \%$ of the FPL.

We appointed a coordinator to manage this program and kept accurate records of the names, medical record numbers, and enrollment dates of current Access Assured members on a daily basis. We provided care for 1 month after membership expired for those patients who chose not to re-enroll in the program, and we carefully tracked re-enrollment as each membership period expired. As part of the Access Assured program evaluation, we have carefully studied many aspects of the program, including sociodemographic and disease characteristics of program enrollees and the financial implications to our practices, some of which were reported in a previous article. ${ }^{3}$ 
After the program's second year, our subjective sense was that patients were grateful the program was available and enrollment in the program was considerable, even though we did no marketing. At the end of the program's first year, 600 patients had enrolled. By the end of the second year, 1258 distinct patients had enrolled for at least one 6-month period, 268 had re-enrolled at least once, and the current enrollment was 406 patients on February 1, 2010. Until we conducted this study, we had no data by which to evaluate patient perceptions of the program. We had anecdotal feedback from patients that they appreciated the program and we knew that a significant number of people had re-enrolled, but we had not embarked on any systematic process to identify ways to improve the patient experience of Access Assured members. Furthermore, we were concerned that the positive feedback we had received might not be representative of the opinions of all the enrollees. Thus, the current study was conducted to gather information regarding the opinions and experiences of Access Assured enrollees, both those who remained enrolled and those who discontinued enrollment. We planned to use the results of this qualitative assessment to decide whether or not to continue the program and to determine how it might be improved.

\section{Methods}

In May 2009, with a protocol approved by the OHSU Institutional Review Board (OHSU eIRB \#4779), we undertook a qualitative study of the Access Assured program using semistructured telephone interviews with selected members of the program. A total of 602 Access Assured enrollees had reached the end of their first 6-month enrollment period by May 1, 2009. We selected a sample of 40 of these patients for our study based on an empiric goal of enrolling at least $5 \%$ of the potential subjects. First, we divided the population into 2 subgroups: 171 members who had re-enrolled after their initial enrollment period and 431 who had not re-enrolled. We chose to sample an equal number of people from these 2 subgroups to maximize the likelihood of collecting negative as well as positive feedback about the program, but it was not a goal of our study to compare these subgroups. The clinical management team generated lists of potential subjects in each subgroup that included only patient names and telephone numbers. The lists of re- enrolled and disenrolled patients were then numerically sorted by telephone number. Patients on both subgroup lists were called in sequential order from these sorted lists up to 3 times (on different days at various times) until 20 patients from each of the 2 subgroups had been successfully interviewed. In total, 64 individuals were called, with 13 wrong numbers, 9 declining participation, 2 who could not participate because of a language barrier, and 40 agreeing to the interview. The portion of potential subjects that we were unable to contact was similar between the 2 groups. There were no financial incentives offered for participation.

\section{Interview Guide Composition}

Guided by our previous research and spontaneous comments from patients during the program's first year, the primary goals of the interviews were to understand patient satisfaction or dissatisfaction with the Access Assured program and to learn why patients chose to re-enroll or not to re-enroll at the end of their initial enrollment periods. We chose a semistructured interview approach, ${ }^{11}$ asking similar questions of all participants and allowing the interviewer to generate unique relevant follow-up questions. This approach allowed us to gain systematic, comparable data in the patient's own words while also allowing the interviewer sufficient flexibility to follow up on interesting and pertinent statements. This semistructured interview guide was composed of 19 questions (see Appendix). Nine questions were directive and aimed to elicit short, factual responses; the other 10 questions were more open-ended and designed to prompt longer and more subjective responses summarizing patients' experiences and perspectives. Subjects were encouraged to expand on their answers to all the questions. The interview questions were devised and pilot tested by OHSU staff, providers from the 2 clinical practices, and medical students to ensure they were easily understandable and that critical elements of the program were included.

\section{The Interviews}

All 40 interviews were conducted by the same interviewer (JH). All subjects were read the same verbal consent form, and the interviewer confirmed verbal consent and answered all questions about the study to each participant's satisfaction before initiating the interview process. All participants who initiated the process completed an interview. Each 
interview lasted 10 to 20 minutes. The interviewer asked questions in the same sequence and used limited inductive probing on key responses. All interviews were audio recorded (with participant agreement) and transcribed verbatim by 2 members of the research team (JH, LS). These 2 researchers proofread the transcripts a total of 3 times to ensure accuracy. All transcripts were then de-identified before being read by the rest of the research team for analysis.

\section{Data Analysis}

After all interviews had been completed and transcribed, the interview transcripts were analyzed by our research team, which included 2 medical students, an administrative staff member, a medical anthropologist, and 2 family physician faculty members. We used the technique of immersion/ crystallization as described by Borkin. ${ }^{12}$ Research team members independently reviewed the transcripts and identified common themes in the text. We then pooled our ideas during 2 in-depth team discussions and reached consensus on 9 themes strongly supported by the data. The research team noted considerable consensus in our assessment of these themes and the pooling process was largely a matter of choosing common names for the themes and choosing whether or not to combine related ones. Three research team members (JWS, JH, RS) then coded the data by again reviewing each transcript line-by-line and assigning these thematic classifications to all pertinent text. The coding of each researcher was then compared with that of the others. Areas of disagreement, for which the researchers assigned different themes to the same text, were resolved through group discussion. This analysis was then replicated using the qualitative analysis software NVivo8 (QSR International, Doncaster, Victoria, Australia), which was used to facilitate further classification and review of the data by team members both individually and together at several subsequent meetings. ${ }^{13}$ This stage of our process allowed us to determine that we had not missed any significant themes in our first analysis of the transcripts.

\section{Results}

The 9 themes identified by our analysis are listed in Table 1. Patient comments that exemplified these themes were selected from the transcripts. Table 1 also lists the number of study participants who mentioned each theme and includes verbatim patient comments that best express each theme. The 9 themes are discussed below.

\section{No Need When Healthy}

Many of the patients did not understand why they should remain enrolled in the program when they were not sick. Some opted not to re-enroll because they did not want to pay for unused services. Others only joined for one time period because they had an urgent medical problem such as the need for a hernia repair or cataract surgery.

\section{Personal Agency}

Though many subjects did not re-enroll because of their financial situation, others failed to do so because they did not complete the paperwork on time or they did not know their enrollment period had expired. Many expressed a desire to be contacted when their membership was nearing expiration. Some experienced miscommunication with the financial assistance administrative staff.

\section{No Choice}

Patients felt pigeonholed by the health system, and viewed Access Assured as their only means to access health care. Some of the patients were already receiving care on a fee-for-service basis at OHSU and could only continue care with their doctors if they enrolled in the program.

\section{Continuity}

Patients reported that they valued being able to choose their doctor and to see the doctor they chose. Many of them expressed considerable loyalty to their family physician and enrolled in the program for this reason.

\section{Respect}

Patients felt they were treated with respect and were not treated differently from other patients because they were uninsured.

\section{Appreciation}

Patients expressed appreciation for the program, particularly that they could access the physician by telephone or E-mail without a visit. 
Table 1. Themes Derived from Patient Comments about the Access Assured Program

\begin{tabular}{lc}
\hline & Description and Number of \\
Study Participants Mentioning & \\
Theme by Enrollment Status & Subjects' Comments \\
\hline
\end{tabular}

1. No Need When Healthy

\section{Personal Agency}

\section{No Choice}

4. Continuity
Subjects did not understand why they needed to be enrolled in the plan during times when they were well.

Mentioned by:

Re-enrolled participants: 8

Not enrolled participants: 8

Subjects expressed varying levels of willingness to assume personal responsibility regarding their enrollment and re-enrollment in the program.

Mentioned by:

Re-enrolled participants: 7

Not enrolled participants: 7

Subjects reported they were not able to access health care as an uninsured person unless they joined a program like Access Assured.

Mentioned by:

Re-enrolled participants: 9

Not enrolled participants: 8

Subjects expressed strong loyalty to their own provider and had varied views on the role Access Assured played in facilitating that relationship.

Mentioned by:

Re-enrolled participants: 7

Not enrolled participants: 5
"I haven't re-enrolled yet because I haven't had a need to see a doctor and your payment is based on the time you see the doctor for a 6-month period, so if I don't need to see a doctor for 6 months, then that money would be toward nothing, so to speak."

"It's like buying insurance; you pay the money and, if you never need the insurance, it's money wasted. But if you need it, it is money well spent."

"Had I been going to the doctor and had I been more healthy, you know, in a healthy state, I probably would be less likely to sign up for it, you know, for the 6-month commitment."

"I screwed the pooch on that one and failed to get my application in on time."

"Nobody's actually really followed up to find out why I didn't fill out the forms or did I receive the forms or whatever. So it kinda's just the fact that it's been left sitting, and I keep getting a bill every month, so I don't understand why nobody is following up to ask me what's going on."

"This is one of those things that's been frustrating for me, watching the health care debate evolve around us and nobody's asking people like me who've been on that edge between insured and uninsured and, you know, what do we want?"

"I really don't have a choice at this point because I need to continue to get my medications refilled so...even if I got a job tomorrow, it would still be 3 months before my insurance would kick in, you know, so I do have to come up with the money and go back on the program so that I can continue my health care."

"Yeah, I'm gonna really have no choice because I love my doctor."

"I don't think being in the Access Assured program has any direct relevance to my health. I would still call my PCP if I needed to be seen. If not, then I would go to urgent care, so... and then probably, you know, follow-up in the office. So, eventually, I would get the care, you know, at the office level but I don't think that it necessarily keeps me or, you know, ensures that I'm gonna go there or not go there if I had the choice."

"If a person is a couple days late with their payment, please don't cancel them completely and take away their ability to see their doctor again, you know. I guess it all comes really down to again that we wouldn't be enjoying this program unless we weren't up against the wall anyway."

“[My enrollment period] has run out and they won't let me get a prescription through my doctor or even talk to a nurse or anything until I renew that, and I've been seeing this doctor for over 14 years. And I just, I just disagree on that. I just don't think that's right."

"I live clear out on 122nd in SE [Portland] and, umm, no matter where I've lived, I've always gone to see Dr. W. or Dr. B., even though I've gotta take more buses to get there. I'd rather go where I know the doctors and they're good to me and they understand chronic pain." 
Table 1. Continued

\begin{tabular}{|c|c|c|}
\hline Theme & $\begin{array}{l}\text { Description and Number of } \\
\text { Study Participants Mentioning } \\
\text { Theme by Enrollment Status }\end{array}$ & Subjects' Comments \\
\hline 5. Respect & $\begin{array}{l}\text { Subjects expressed gratification } \\
\text { for the appearance of } \\
\text { consistent medical care } \\
\text { between uninsured and } \\
\text { insured patients. } \\
\text { Mentioned by: } \\
\text { Re-enrolled participants: } 5 \\
\text { Not enrolled participants: } 4\end{array}$ & $\begin{array}{l}\text { "I was treated very well. They still don't, you know-they } \\
\text { didn't change their medical practices because I was } \\
\text { uninsured... huge relief! Because a lot of doctors do } \\
\text { that...outside of OHSU-but they still treated me just like } \\
\text { any other patient." } \\
\text { "They're doing much better now than they were when I first } \\
\text { started, you know, but when I first started, and the } \\
\text { program first came out, I felt like I was treated, umm, } \\
\text { differently amongst normal patients. You know like, } \\
\text { umm-I just-maybe, like I was a disease or something." }\end{array}$ \\
\hline 6. Appreciation & $\begin{array}{l}\text { Subjects expressed appreciation } \\
\text { for the program and were } \\
\text { grateful to have access to care. } \\
\text { Mentioned by: } \\
\text { Re-enrolled participants: } 11 \\
\text { Not enrolled participants: } 10\end{array}$ & $\begin{array}{l}\text { "Before I see them my count of diabetes wasn't that good } \\
\text { and practically I was fully blind-I could not drive-and } \\
\text { everything is come down, I can see } 20 / 20 \text { now and I } \\
\text { appreciated the doctor who did this service to me. My } \\
\text { diabetes came down and I realize what kind of food I have } \\
\text { to eat to come down my diabetes to stay in the same } \\
\text { number." } \\
\text { "Well, I-I've lost a significant amount of weight and I } \\
\text { stopped drinking so, umm, that's kind of on the personal } \\
\text { side, but, yeah, I've definitely improved in my health." } \\
\text { "For the most part it makes me feel comfortable! I have } \\
\text { access! I have access to medical! I have access to medical } \\
\text { care without having to worry about money... You know } \\
\$ 350 \text { is a lot better than } \$ 1500 \text { or so, you know?" } \\
\text { "It's a marvelous service to have for people who don't have } \\
\text { full-on insurance and there's a lot of us. So, I'm just really } \\
\text { grateful that it's available." }\end{array}$ \\
\hline 7. Quality of Care & $\begin{array}{l}\text { Subjects had both negative and } \\
\text { positive comments about the } \\
\text { quality of care and services } \\
\text { received. } \\
\text { Mentioned by: } \\
\text { Re-enrolled participants: } 17 \\
\text { Not enrolled participants: } 16\end{array}$ & $\begin{array}{l}\text { "I was completely hopeless that I didn't have a doctor and I } \\
\text { didn't have anybody to listen to me or take care of me, so } \\
\text { when I joined OHSU, and then I was relieved emotionally } \\
\text { that I am in the hands of a professional and caring people, } \\
\text { that when I am sick there was somewhere to go and some } \\
\text { people nice...to help me." } \\
\text { "The people were extremely courteous. Extremely nice. } \\
\text { Things moved along. Actually when you went there wasn't } \\
\text { much of a wait. Just the staff in general made you feel } \\
\text { comfortable. Even the doctor. Just basically I like the } \\
\text { people but it seemed easier to go right down to the } \\
\text { bottom...to deal with folks. It just seemed like their } \\
\text { attitudes were better or something. I don't quite know } \\
\text { how to put my finger on that." } \\
\text { "It's much nicer if you can sit and speak to a doctor instead } \\
\text { of...talking to them while they're typing into a machine." }\end{array}$ \\
\hline $\begin{array}{l}\text { 8. Confusion and } \\
\text { Transparency }\end{array}$ & $\begin{array}{l}\text { Subjects reported confusion } \\
\text { about the terms of the } \\
\text { program, including a lack of } \\
\text { understanding of their } \\
\text { enrollment periods, benefits, } \\
\text { and sliding scale fees } \\
\text { depending on their income. } \\
\text { Mentioned by: } \\
\text { Re-enrolled participants: } 8 \\
\text { Not enrolled participants: } 10\end{array}$ & $\begin{array}{l}\text { "I thought this } \$ 150 \text { every } 6 \text { months was automatic based on } \\
\text { the period of our application for OHSU financial } \\
\text { assistance. I never requested Access Assured; it was all just } \\
\text { like-it all ran together." } \\
\text { "It's possible that they gave me the information but, like I } \\
\text { said, I was so sick at the time. I just needed to be seen so, } \\
\text { I mean, that's what I did. I signed the paper so that I } \\
\text { could be seen. I didn't read it very well. It might have } \\
\text { been in the information. I don't know." } \\
\text { "They directed me to other people who thought they could } \\
\text { tell me what was covered and then those people didn't } \\
\text { know and directed me somewhere else and it turned out } \\
\text { nobody really knew. That's what should change." }\end{array}$ \\
\hline
\end{tabular}


Table 1. Continued

\begin{tabular}{|c|c|c|}
\hline Theme & $\begin{array}{l}\text { Description and Number of } \\
\text { Study Participants Mentioning } \\
\text { Theme by Enrollment Status }\end{array}$ & Subjects' Comments \\
\hline 9. Economic Stress & $\begin{array}{l}\text { Subjects reported a wide range } \\
\text { of personal and family } \\
\text { economic stress, including job } \\
\text { loss, debt, and the high cost } \\
\text { of health care to them } \\
\text { personally. } \\
\text { Mentioned by: } \\
\text { Re-enrolled participants: } 18 \\
\text { Not enrolled participants: } 20\end{array}$ & $\begin{array}{l}\text { "It was still too expensive for low-income people, but at least } \\
\text { it was something." } \\
\text { "We cannot predict the future and the costs of medical has } \\
\text { gone completely out of sight. Absolutely ridiculous. And if } \\
\text { one gets sick, you're certainly in debt for the rest of your } \\
\text { life-and your family after that to pay off your medical } \\
\text { bills." } \\
\text { "Coming up with \$75 is hard enough, but coming up with } \\
\$ 150 \text { is just scary. It means food or not. I mean, it's scary." } \\
\text { "Yeah, I was a Union Sheet Metal journeyman for like 13, } \\
14 \text { years; had Blue Cross Blue Shield and, uh, I never got } \\
\text { sick and I never used it once. Yeah...and then I had the } \\
\text { Oregon Health Plan (Medicaid) after that, umm...and } \\
\text { then I made too much money at minimum wage and I } \\
\text { basically was without health care at all and I had the stroke } \\
\text { without health care; that's why I didn't go to the hospital." } \\
\text { "I was a student at Portland State, and I, uh, I had a hernia } \\
\text { erupt... My plan was to drop out of school, get a job, and } \\
\text { get health insurance so I could get covered and last year } \\
\text { simply was not a good year and I've been several months } \\
\text { between contracts. I'm in software, [information } \\
\text { technology], computer programming, that sort of thing, so } \\
\text { it is a lot of contract work for people starting out. And, } \\
\text { again, uh, you know, here's your } 2-\text { or } 3 \text {-month contract } \\
\text { and it's } 90 \text { days before you can get health insurance and } \\
\text { that sort of thing." }\end{array}$ \\
\hline
\end{tabular}

OHSU, Oregon Health \& Science University.

\section{Quality of Care}

Patients had both positive and negative comments about the quality of care and service they received. Some did not appreciate physicians using a computer during the office visit; others complained that their visits were interrupted with cell phone calls, they did not like seeing medical students, or they were refused medications. Some patients found it hard to get in contact with their physician or had trouble getting needed prescription refills, whereas others shared very positive experiences. Many expressed they did not have enough time with the physician and some wished physicians would work longer hours. Others felt they saw too many different physicians, but many were confident that they received quality care.

\section{Confusion and Transparency}

Patients often did not understand Access Assured and reported confusion about its terms and benefits even though the program was explained in writing when they enrolled.

\section{Economic Stress}

Patients enrolled in Access Assured were often under substantial economic stress and many struggled to afford the program.

In general, we found few differences in the responses to our questions between patients who had and had not re-enrolled in Access Assured. Both groups of patients expressed the same general themes in their replies. Interestingly, 11 of the 20 subjects who had not re-enrolled in Access Assured indicated a desire to re-enroll during the interview. Three of the remaining 9 patients who did not re-enroll became enrolled in employer-sponsored health insurance or Medicaid and no longer needed Access Assured.

\section{Discussion}

Our study goal was to learn about the broad perceptions of Access Assured patients regarding the program and to use this information to improve the program. Even though half of the patients we interviewed were selected from those who had not re-enrolled in the program, most expressed pos- 
itive overall opinions. The subjects we interviewed were generally appreciative, believed they received good-quality service, valued continuity with a clinic and/or physician, and felt respected as patients deserving of care.

Why would people be happy with the program and yet not re-enroll as a member? This apparent contradiction might be explained by several factors. Some of these patients became eligible for Medicaid or commercial insurance. Three of the patients told us that this was the case for them. Others might have chosen to avoid the membership fee until the next time they needed to visit a physician, a hypothesis supported by the first theme in our results (No Need When Healthy). Thirty-eight of the 40 subjects interviewed mentioned economic stress as a factor in their experience with Access Assured. It is possible that a number of patients chose to avoid the membership fee for this reason. This might also explain why more than half of the subjects who had not re-enrolled told us they intended to do so if they need care in the future. This finding suggests that convincing economically challenged patients to remain enrolled in a retainer program during time periods when they do not need to visit the clinic is a significant challenge to such programs.

Program participants were confused about the program's terms and conditions. Our written materials were designed to be understandable to those with limited reading levels, but it is possible we overestimated their health literacy. Based on these results, we have worked to improve these materials and the ability of our clinic staff to explain them.

Our study has at least 2 important limitations. First, it examines patient opinions about a very specific program developed in only 2 clinics at a single university family medicine program rather than their reactions to the idea of retainer programs in general. Thus, it is unclear how relevant these results might be for other types of retainer programs in other settings. Second, the first cohort of enrollees were probably people who had been without health care for some time, so they might have had atypically positive opinions because of their gratitude for receiving care at all. We tried to minimize this bias by purposefully choosing half of the subjects from the cohort of patients who chose not to re-enroll in the program.

Our findings suggest that Access Assured has been well received by our patients, and this finding is consistent with our anecdotal experience. Our previous article showed that the program is financially viable. ${ }^{3}$ This qualitative study suggests that most of those who enrolled in the program were willing to continue to participate after their initial enrollment period ended, even those who had not yet renewed enrollment at the time of their telephone interviews for this study. Based on these results, we plan to continue this program and we have made several modifications regarding how we explain it to potential enrollees. Our 2-year experience with Access Assured suggests that this model might be useful for other primary care practices faced with the challenge of caring for the uninsured.

At a health policy level, our study suggests that a retainer payment system may provide a workable model of primary care for the uninsured and underinsured while health reform proceeds. In the longer term, if health reform initiatives succeed in extending health insurance coverage to almost all Americans, this type of alternative financing model may not be needed. However, if the most affordable health insurance plans offered by insurance exchanges have high deductibles and other high cost-sharing ratios, a program like Access Assured that guarantees access to a comprehensive basket of primary care services could become even more relevant.

Regardless of how the insurance system is transformed, the delivery system lacks capacity and a shortage of primary care looms. ${ }^{14,15}$ An increasing number of patients, both insured and uninsured, cannot find primary care physicians, and both physicians and patients struggle with an increasingly burdensome and costly insurance bureaucracy. The cost of fee-for-service billing is a substantial burden to primary care practices, and such costs might be reduced or eliminated by a retainer payment system. Thus, a sustainable business model that allows primary care providers to care for everyone in the community is needed badly. Our limited experience with Access Assured demonstrates that a retainer financing system can be successful, even for low-income patients.

Because early research about retainer practices identified physician concerns about the ethics of such payment systems, ${ }^{8,16}$ further research should be conducted to assess physician experiences with such programs. If retainer models can be developed that provide access for everyone, these models 
might appeal to a broader audience of physicians and may also stimulate the interest of our students in new models of primary care.

\section{References}

1. Dubay L, Holahan J, Cook A. The uninsured and the affordability of health insurance coverage. Health Aff 2006;26(1):w22-w30.

2. Dentzer S. Reinventing primary care: a task that is too important to fail. Health Aff 2010;29(5):757.

3. Saultz JW, Brown D, Stenberg S, et al. Access assured: a pilot program to finance primary care for uninsured patients using a monthly enrollment fee. J Am Board Fam Med 2010;23:393-401.

4. Lucier DJ, Frisch NB, Cohen BJ, Wagner M, Salem D, Fairchild DG. Academic retainer medicine: an innovative business model for cross-subsidizing primary care. Acad Med 2010;85:959-64.

5. Alexander GC, Kurtlander J, Wynia MK. Physicians in retainer ("concierge") practice: a national survey of physician, patient, and practice characteristics. J Gen Intern Med 2005;20:1079-83.

6. Linz AJ, Halas PF, Fallon LF, Metz RJ. Impact of concierge care on healthcare and clinical practice. J Am Osteopath Assoc 2005;105:515-20.

7. Brennan TA. Luxury primary care market innovation or threat to access? N Engl J Med 2002;346: 1165-8.

8. Reinhardt UE. The emergence of "boutique medicine." BMJ 2002;2:468.

9. Wu WN, Bliss G, Bliss EB, Green LA. Practice profile. A direct primary care medical home: the Qliance experience. Health Aff (Milwood) 2010; 29(5):959-62.

10. Fed Regist 2009;74(14):4199-201.

11. Patton MQ. Qualitative evaluation and research methods, 2nd ed. Newbury Park, CA: Sage Publications; 1990.

12. Borkan J. Immersion/crystallization. In: Crabtree BF, Miller WL. Doing qualitative research. Thousand Oaks, CA: Sage Publications; 1999.

13. QRS International. NVivo 9. Available at: http:// www.qsrinternational.com/products_nvivo.aspx. Accessed 6 February 2010.

14. Bodenheimer T, Pham HH. Primary care: current problems and proposed solutions. Health Aff (Milwood) 2010;29(5):799-805.
15. Phillips RL, Bazemore AW. Primary care and why it matters for US health system reform. Health Aff (Milwood) 2010;29(5):806-10.

16. Brennan TA. Luxury primary care- market innovation or threat to access? N Engl J Med 2002;346(15): 1165-8.

\section{Appendix. Interview Guide Questions}

1. What sorts of things did you consider when deciding whether to sign up for Access Assured?

2. Now that you have been a part of the program, how has it been working for you?

3. What is (or was) the most convenient aspect(s) of the program?

4. What is (or was) the most inconvenient aspect(s) of the program?

5. How do you feel about the actual health care you have received?

6. How do you feel about the administrative processes and personnel?

7. How do you (or did you) usually access the care you received in Access Assured (eg, clinic visits, telephone calls, and/or internet-based care)? How did that work for you?

8. How do you feel your use of health care compares to other people? How much did you use the health care services available to you?

9. Do you feel that your overall health has improved, worsened, or stayed the same since you enrolled in Access Assured? What do you think that is due to?

10. Do you plan to re-enroll at the end of your current enrollment? Or, why did you choose not to re-enroll?

11. How can we make (or could we have made) Access Assured better for you?

12. Did you have health insurance before your enrollment in Access Assured?

13. Did you have a primary care provider before your enrollment in Access Assured?

14. Did you use the emergency room or urgent care clinics during your enrollment in Access Assured?

15. Did you use the emergency room or urgent care clinics before your enrollment in Access Assured?

16. Did your job status change since you enrolled in Access Assured?

17. Did your health care insurance status change since you enrolled in Access Assured?

18. Does the program - the way it is set up and the reasons for the membership fee- make sense to you? Do you have any other questions about the Access Assured Program?

19. Would you like us to call you or send you email from time to time to update you about Access Assured (such as reminders about re-enrollment)? 